\title{
Glück und das neoliberale Recht auf Unglück
}

Es wäre eine Leitkultur, deren oberster Wert es ist, möglichst vielen möglichst viele Möglichkeiten zu eröffnen, und da-

Oder möglichst vielen möglichst viel Glück? Mir scheint, wir sind gerade im Hochsicherheitstrakt unsres Themas angekommen.

Lass mir die Utilitaristen aus dem Spiel! Fürs Glück des andern ist niemand zuständig ausser dieser andere selbst, am allerwenigsten der Staat. Also noch mal: Wir sind auf gutem Wege zu einer Leitkultur, die möglichst vielen möglichst viele Möglichkeiten eröffnet: Nie war in einer Kultur mehr möglich als in der unseren. Mit allen Schattenseiten: Die Möglichkeiten machen das Unglück ebenso wahrscheinlich wie das Glück. Worauf ich aber hinauswill: Die Leitkultur der Möglichkeitspluralität bezieht den zivilen Ungehorsam als eine ihrer Möglichkeiten ein. Wobei die Betonung auf «zivil» liegt: Der Ungehorsam darf niemanden gewaltsam an seinen Möglichkeiten hindern. Und das Einbeziehen der Möglichkeit zivilen Ungehorsams bedeutet nicht, dass dieser Ungehorsam straffrei wäre. Wer diese Möglichkeit ergreift, muss damit rechnen, belangt zu werden. Man kann zivilen Ungehorsam moralisch billigen und ihn doch strafrechtlich verurteilen.

Im Prinzip gebe ich Dir hier recht, auch wenn ich befürchte, daß Du gerade ein bißchen neoliberal rübergekommen bist. Ich bin selber keiner, der nach Mitternacht gern vor roten Fußgängerampeln wartet, wenn ich's mal bei dieser Andeutung belassen darf. Im Gegenteil, gelegentliche Grenzüberschreitung hält den Geist flexibel, nicht zuletzt konterkariert sie das Bild vom ordnungshörigen Deutschen, über den im Ausland gern gelacht wird. In Sachen Eigenmächtigkeit, Unbotmäßigkeit, Regelverstoß haben wir ab der 68er-Generation kräftig dazugelernt - das ist unsre neue Leitkultur, jedenfalls, wenn sich "progressive" Kräfte zu erkennen geben. 
Deine 68er-Reverenz mal ausgeklammert - Du bist doch ein $78 \mathrm{er}$ und weisst überdies, dass die Avantgarden der vorvorigen Jahrhundertwende und der Weimarer Republik viel aufmüpfiger waren als die maoistisch-marxistischen Spiesser von 1968. Vielleicht waren ja auch schon diese vorvorigen Avantgarden «neoliberal»: freie Fahrt für freies Denken. Aber das Problem ist doch: Auch die Rechten operieren vorzugsweise mit Regelverstössen, es ist auch ein Erkennungszeichen reaktionärer Kräfte.

\section{Bonuspunkte für Herdentiere}

Also zurück zu den Linken, den Vertretern der linken Blase, die ihrem Tun zwar mit der Etikettierung als "empathisch", "lustvoll« oder "spielerisch" ein geschicktes Framing durch positive Begriffe verpaßt haben, damit aber, wie gesagt, ein beinhart ideologisches Projekt durchziehen. Vielleicht kommen wir auf die sprachliche Verschleierung später zu sprechen, im Moment geht es uns ja um die Sache dahinter, um den ideologisch gerechtfertigten, den politisch korrekten Ungehorsam. Er macht uns Deutsche nur scheinbar sympathisch, schließlich eifern wir damit vornehmlich unserem eigenen Bild von Weltbürgertum nach! Fast überall sonst auf der Welt - so habe ich es auf meinen Reisen erfahren - wird den Regeln des Zusammenlebens ein weit höherer Wert zugeschrieben als bei uns, achtet der einzelne weit mehr auf die Gemeinschaft.

Vielleicht in Japan, das hier tatsächlich Weltmarktführer ist; aber schon in China wird es doch merklich ruppiger, oder nicht? Und erst in Afrika ...

Nicht unbedingt. Ich war gerade für zwei Monate in Shanghai, und natürlich geht's da manchmal recht zielstrebig zur Sache. Aber doch nie mit dieser Aggressivität, wie wir sie in Deutschland an den Tag legen. Ehrlich gesagt, ich habe mich wohler ge- 